\title{
Practical Algorithms in Pediatric Nephrology
}

Editors

Israel Zelikovic, Haifa

Israel Eisenstein, Haifa

56 graphs, 1 figure and 10 tables, 2008 


\section{Contents}

1 Contributors

2 Preface

Z. Hochberg

3 Introduction

I. Zelikovic; I. Eisenstein

\section{Glomerular and vascular disease}

4 Hematuria

A.L. Friedman; S. Turi

6 Acute nephritic syndrome

F. Santos; S.P. Makker

8 Proteinuria

F. Santos; S.P. Makker

10 Nephrotic syndrome in the first year of life

F. Santos; S.P. Makker

12 Nephrotic syndrome in the child and adolescent

S.P. Makker; F. Santos

14 Rapidly progressive glomerulonephritis S.P. Makker; F. Santos

16 Chronic nephritic syndrome S.P. Makker; F. Santos

18 Vasculitis

W. Proesmans; U.S. Alon

20 Hemolytic uremic syndrome W. Proesmans; U.S. Alon

\section{Urinary tract disease/tubulointerstitial} nephropathy

22 Urinary tract infection

R. Adelman; S. Hulton

24 Dilated/obstructed urinary tract S. Hulton; R. Adelman

26 Fetal hydronephrosis J.-P. Guignard: R.N. Fine

28 Vesicourethral reflux R. Adelman; S. Hulton

30 Dysfunctional voiding S. Hulton; R. Adelman

32 Loin pain with hematuria J. Smith; F.B. Stapleton

34 Renal trauma R. Adelman; S. Hulton

36 Tubulointerstitial nephritis A.L. Friedman; S. Turi

\section{Structural/congenital abnormalities}

38 Single kidney (renal agenesis) G. Rizzoni ${ }^{\dagger}$; M.A. Linshaw

40 Renal hypoplasia-dysplasia G. Rizzoni ; M.A. Linshaw

42 Nephromegaly M.A. Linshaw; G. Rizzoni ${ }^{\dagger}$

44 Hyperechoic kidney M.A. Linshaw; G. Rizzoni ${ }^{\dagger}$

46 Cystic kidneys

G. Rizzoni ${ }^{\dagger}$; M.A. Linshaw

48 Renal mass

M.A. Linshaw; G. Rizzoni ${ }^{\dagger}$

\section{Hypertension}

50 Neonatal hypertension S. Turi; A.L. Friedman

52 Pediatric hypertension S. Turi; A.L. Friedman

\section{Tubular disease}

54 Aminoaciduria

I. Eisenstein; P. Goodyer; I. Zelikovic

56 Cystinuria

P. Goodyer; I. Eisenstein; I. Zelikovic

58 Glycosuria

I. Eisenstein; P. Goodyer; I. Zelikovic

60 Renal tubular acidosis

I. Eisenstein; P. Goodyer; I. Zelikovic

62 Proximal tubulopathy

(Fanconi syndrome)

P. Goodyer; I. Eisenstein; I. Zelikovic

64 Polyuria

P. Goodyer; I. Eisenstein; I. Zelikovic

66 Hypouricemia J. Smith; F.B. Stapleton

68 Hyperuricemia F.B. Stapleton; J. Smith

70 Rickets

G. Ariceta; B. Hoppe; C.B. Langman 


\section{Fluid/electrolyte/acid base balance}

\section{Hyponatremia}

S. Watkins; D. Okamura; J. Rodríguez Soriano

74 Hypernatremia

S. Watkins; D. Okamura; J. Rodríguez Soriano

76 Hypochloremia

J. Rodríguez Soriano; D. Okamura; S. Watkins

78 Hyperchloremia

D. Okamura; J. Rodríguez Soriano; S. Watkins

80 Hypokalemia

D. Okamura; J. Rodríguez Soriano; S. Watkins

82 Hyperkalemia

J. Rodríguez Soriano; D. Okamura; S. Watkins

84 Metabolic acidosis

U.S. Alon; W. Proesmans

86 Metabolic alkalosis

U.S. Alon; W. Proesmans

88 Hypovolemia

U.S. Alon; W. Proesmans

90 Edema

W. Proesmans; U.S. Alon

\section{Divalent ion metabolism}

92 Hypocalcemia

G. Ariceta; B. Hoppe; C.B. Langman

94 Hypercalcemia

B. Hoppe; G. Ariceta; C.B. Langman

96 Hypophosphatemia

C.B. Langman; G. Ariceta; B. Hoppe

98 Hyperphosphatemia C.B. Langman; G. Ariceta; B. Hoppe

100 Hypomagnesemia

I. Eisenstein; P. Goodyer; I. Zelikovic

102 Hypercalciuria F.B. Stapleton; J. Smith

104 Nephrolithiasis/urolithiasis F.B. Stapleton; J. Smith

\section{Renal failure}

106 Oliguria/anuria J.-P. Guignard; R.N. Fine

108 Neonatal acute renal failure J.-P. Guignard; R.N. Fine

110 Acute renal failure (child/adolescent) R.N. Fine; J.-P. Guignard

112 Chronic renal failure R.N. Fine; J.-P. Guignard

114 Renal osteodystrophy R.N. Fine; J.-P. Guignard

116 Index of Signs and Symptoms

120 Abbreviations 
Library of Congress Cataloging-in-Publication Data

Practical algorithms in pediatric nephrology / editors, Israel Zelikovic srael Eisenstein.

p.; $; \mathrm{cm}^{---}$(Practical algorithms in pediatrics)

ISBN 978-3-8055-8539-2 (soft cover : alk. paper)

1. Pediatric nephrology--Handbooks, manuals, etc. 2. Medic

protocols--Handbooks, manuals, etc. I. Zelikovic, Israel. II. Eisenstein

srael, 1964- III. Series.

IDNLM: 1. Kidney Diseases--diagnosis. 2. Adolescent. 3. Child. 4.

$618.92^{\prime} 61--d c 22$

2008019859
Disclaimer. The statements, options and data contained in this publi cation are solely those of the individual authors and contributors an ments in the book is not a warranty, endorsement or approval of the products or services advertised or of their effectiveness, quality or safety. The publisher and the editor(s) disclaim responsibility for any injury to persons or property resulting from any ideas, methods, instructions or products referred to in the content or advertisements.

Drug Dosage. The authors and the publisher have exerted every effor to ensure that drug selection and dosage set forth in this text are in accord with current recommendations and practice at the time of pubregulations, and the constant flow of information relating to drug ther apy and drug reactions, the reader is urged to check the package inser for each drug for any change in indications and dosage and for added warnings and precautions. This is particularly important when the recommended agent is a new and/or infrequently employed drug.
All rights reserved. No part of this publication may be translated into other languages, reproduced or utilized in any form or by any means, copying, or by anyinfar, nation stg poupying, recording, mithopermission in writing from the publisher.

(c) Copyright 2008 by S. Karger AG, P.O. Box, CH-4009 Basel

(Switzerland)
Printed in Switzerland on acid-free and non-aging paper (ISO 9706)

by Reinhardt Druck, Basel 


\section{Contributors}

Raymond Adelman, MD

Department of Pediatrics

Phoenix Children's Hospital

Phoenix, AZ, USA

\section{Uri S. Alon, MD}

Section of Pediatric Nephrology

The Children's Mercy Hospital and Clinics

University of Missouri

Kansas City, MO, USA

\section{Gema Ariceta, MD}

Division of Pediatric Nephrology

Hospital de Cruces

Baracaldo, Vizcaya, Spain

Israel Eisenstein, MD

Pediatric Nephrology

Rambam Medical Cente

Faculty of Medicine - Technion

Haifa, Israel

\section{Richard N. Fine, MD}

School of Medicine

State University of New York at Stony Brook

Stony Brook, NY, USA

\section{Aaron L. Friedman, MD}

Department of Pediatrics

University of Minnesota

Minneapolis, MN, USA

\section{Paul Goodyer, MD}

Division of Pediatric Nephrology

The Montreal Children's Hospital

McGill University

Montreal, Quebec, Canada

Jean-Pierre Guignard, MD

Division of Pediatric Nephrology

Department of Pediatrics

Lausanne University Medical School

Lausanne, Switzerland

\section{Bernd Hoppe, MD}

University Children's Hospital

Division of Pediatric Nephrology

Cologne, Germany

\section{Sally Hulton, MD}

Department of Pediatric Nephrology

The Birmingham Children's Hospital

NHS Trust

Birmingham, United Kingdom

Craig B. Langman, MD

Feinberg School of Medicine

Northwestern University

Kidney Diseases, Children's Memorial Hospital Chicago, IL, USA

Michael A. Linshaw, MD

Division of Pediatric Nephrology

Massachusetts General Hospita

Boston, MA, USA

Sudesh Paul Makker, MD

Pediatric Nephrology

UC Davis Medical Center

Sacramento, CA, USA

\section{Daryl Okamura, MD}

Division of Pediatric Nephrology

Children's Hospital and Regional Medical Center

University of Washington

Seattle, WA, USA

Willem Proesmans, MD

Renal Unit, Department of Pediatrics

University Hospital Gasthuisberg

Leuven, Belgium

\section{Gianfranco Rizzoni ${ }^{\dagger}, \mathrm{MD}$}

Division of Nephrology

Children's Hospital and

Research Institute Bambino Gesu

Rome, Italy
Juan Rodríguez Soriano, MD

Division of Pediatric Nephrology

Department of Pediatrics

Hospital de Cruces and Basque University

School of Medicine

Baracaldo, Vizcaya, Spain

Fernando Santos, MD

Division of Pediatric Nephrology

Hospital Central de Asturias

University of Oviedo

Oviedo, Asturias, Spain

Jodi Smith, MD

Division of Pediatric Nephrology

Children's Hospital and Regional Medical Center

University of Washington

Seattle, WA, USA

\section{F. Bruder Stapleton, MD}

Department of Pediatrics

Children's Hospital and Regional Medical Center

University of Washington

Seattle, WA, USA

\section{Sandor Turi, MD}

Department of Pediatrics and Child Health Center University of Szeged

Szeged, Hungary

\section{Sandra Watkins, MD}

Division of Pediatric Nephrology

Children's Hospital and Regional Medical Center University of Washington

Seattle, WA, USA

Israel Zelikovic, MD

Pediatric Nephrology

Rambam Medical Center

Faculty of Medicine - Technion

Haifa, Israel 


\section{Preface}

The term 'algorithm' is derived from the name of the ninth century Arabic mathematician Algawrismi, who also gave his name to 'algebra'. His 'algorismus', indicated a well-defined procedure for step-bystep logical approach to mathematical problem-solving. In reading the final product, written by some of the finest pediatric nephrologists in the world and edited by my friends Drs. Israel Zelikovic and Israe Eisenstein, it is obvious that the spirit of the algorismus has been utilized in its best. The algorithm input are physical symptoms and signs, or laboratory results, which lead to a number of effective steps, and produces the diagnoses for an output.
Practical Algorithms in Pediatric Nephrology is meant as a pragmatic text to be used at the patient's bedside. The experienced practitioner applies step-by-step logical problem-solving for each patient individually. Decision trees prepared in advance have the disadvantage of unacquaintedness with the individual patient Yet, for the physician who is less experienced with a given problem, a prepared algorithm would provide a logical, concise, cost-effective approach prepared by a specialist who is experienced with the given problem.

Thirty years after completing my pediatric residency, I discover that Pediatric Nephrology has become a sophisticated specialty with solid scientific background of which I know so little. I would still refer my patients to a specialist with many of the diagnoses, symptoms and signs discussed here. But, with the help of this outstanding algorithms and text, I would refer them after an educated initial workup, and would be better equipped to follow the specialist's management.
This is the third in the Series of Practical Algorithms in Pediatrics, following Practical Algorithms in Pediatric Endocrinology and Practical Algorithms in Pediatric Hematology-Oncology. Hopefully, this volume will provide residents, fellows, general pediatricians and family practitioners some important clinical tools in understanding their patients.

\section{Ze'ev Hochberg, MD, PhD}

Series Editor 


\section{Introduction}

Practical Algorithms in Pediatric Nephrology is a pragmatic text which classifies common clinical symptoms, signs, laboratory abnormalities and issues of management as they present themselves in daily practice. Aimed at an audience of general and family practitioners, pediatricians and trainees who are not exposed to pediatric nephrology problems on a day-today basis, it provides a rational, stepwise and as noninvasive as possible approach from which they can profit and acquire medical reasoning.

In the past decade, remarkable progress has been made in our understanding of the molecular pathogenesis of hereditary kidney diseases and congenital urinary tract abnormalities. Studies in molecular genetics and molecular biology have led to the identification of numerous kidney disease-causing mutations, provided important insights into the defective molecular mechanisms underlying various kidney diseases and structural abnormalities of the kidney, and have greatly increased our understanding of the physiology and pathophysiology of renal function in health and disease. Hence, special emphasis has been given in this book to the novel knowledge that has accumulated on the molecular pathophysiology and molecular genetics of various kidney diseases and urinary tract abnormalities, in order to deepen and strengthen the practical approach to com mon problems occurring in pediatric nephrology. Indeed, many of the algorithms in this book, written by leading investigators in the area of pediatric nephrology, incorporate and exemplify this 'bench to patient' approach which has become a characteristic of modern medicine.

It is the Editors' hope that the algorithmic, logical and stepwise approach to the diagnosis and management of various hereditary and acquired kidney diseases, fluid and electrolyte abnormalities, aberrations in mineral balance, and other impairments in kidney function, will equip the practitioner, inexperienced in the field of pediatric nephrology, with the tools and ability to successfully confront and manage, at least at their initial stages, clinical problems which have always been notorious for their complexity and which have been left, from the outset, to specialists in the area.
During the production process of this book, it has been our privilege to interact and work with some of the leading clinicians and teachers in the field of pediatric nephrology in the world. It has been a very enriching and gratifying experience for us, the editors, for which we thank all the authors. A final note - we have been very saddened by the recent passing of Prof. Gianfranco Rizzoni, a prominent pediatric nephrologist from Rome, Italy, who contributed several excellent algorithms to this book. We send our deep condolences to his family and friends.

Israel Zelikovic, MD

Israel Eisenstein, MD 